\title{
Estrogen Influences Cocaine-Induced Blood Oxygen Level- Dependent Signal Changes in Female Rats
}

\author{
Marcelo Febo, ${ }^{1}$ Craig F. Ferris, ${ }^{1}$ and Annabell C. Segarra ${ }^{2}$ \\ ${ }^{1}$ Center for Comparative NeuroImaging, Department of Psychiatry, University of Massachusetts Medical School, Worcester, Massachusetts 01655, and \\ ${ }^{2}$ Department of Physiology and Biophysics, University of Puerto Rico Medical School, San Juan, Puerto Rico 00936
}

\begin{abstract}
We investigated the effect of estrogen on cocaine-induced brain activity using blood oxygen level-dependent (BOLD) magnetic resonance imaging. Ovariectomized $(\mathrm{Ovx})$ rats without estrogen and $\mathrm{Ovx}$ rats with estrogen $(\mathrm{Ovx}+\mathrm{E})$ were given a single saline or cocaine injection $(15 \mathrm{mg} / \mathrm{kg}$, i.p.) for $5 \mathrm{~d}$. After $7 \mathrm{~d}$ of withdrawal from injections, rats were challenged with cocaine during functional imaging. Acute cocaine administration produced positive BOLD activation in the prefrontal cortex, nucleus accumbens, striatum, ventral tegmental area, and hippocampus, among other brain regions. Positive BOLD signal changes were lower in Ovx $+\mathrm{E}$ than in Ovx rats. With repeated cocaine administration, $0 v x+E$ rats showed enhanced BOLD signal changes in the nucleus accumbens, ventral tegmental area, and hippocampus compared with acutely treated animals. Our results indicate that estrogen influences the effects of acute and repeated cocaine administration on BOLD signal changes. The data suggest that in females with estrogen, cocaine-induced neuronal activity is enhanced after repeated cocaine administration. It is possible that the actions of estrogen within the aforementioned brain regions potentiate the behavioral response to cocaine observed in female rats.
\end{abstract}

Key words: cocaine sensitization; female rats; estrogen; functional magnetic resonance imaging; BOLD signal; sex differences; VTA; cerebral blood flow; nucleus accumbens; hippocampus; hypercapnia; radiofrequency electronics

\section{Introduction}

Female rats display greater behavioral sensitization to cocaine than do males (Sircar and Kim, 1999; Chin et al., 2002; Hu and Becker, 2003). Estrogen, the main female gonadal hormone, appears to be the critical chemical signal altering the behavioral response to cocaine (Becker, 1999). Estrogen has been shown to enhance behavioral sensitization to cocaine (Chin et al., 2002; Hu and Becker, 2003) and cocaine self-administration in females (Lynch et al., 2001). The current evidence indicates that this sex steroid interacts with many neurotransmitter systems that are also affected by repeated cocaine administration. These include dopamine (Febo et al., 2003), opioid (Febo et al., 2002), serotonin (Chang and Chang, 1999), GABA (Lagrange et al., 1996; Febo and Segarra, 2004), and glutamate (Woolley et al., 1997) systems. The modulatory actions of estrogen extend beyond the mesolimbic dopamine system into brain areas that play crucial roles in behavioral sensitization, such as the hippocampus and prefrontal cortex (Woolley et al., 1997; Shansky et al., 2003; Tang et al., 2004). Therefore, estrogen can affect neuronal activity across many re-

Received June 16, 2004; revised Dec. 20, 2004; accepted Dec. 20, 2004.

This work was partially funded by National Institutes of Health-National Institute on Drug Abuse (NIDA) Grant R01 DA13517 to C.F.F. and by a National Institute of Neurological Disorders and Stroke (NINDS) grant (Specialized Neuroscience Research Program U54 NS39405) to A.C.S. A NIDA Minority Supplement Award provided support for M.F. Its contents are solely the responsibility of the authors and do not necessarily represent the official views of NIDA and NINDS.

Correspondence should be addressed to Dr. Marcelo Febo, Center for Comparative Neurolmaging (CCNI), University of Massachusetts Medical School, 303 Belmont Street, CCNI Building, Worcester, MA 01604. E-mail: Marcelo.Febo@umassmed.edu.

DOI:10.1523/JNEUROSCI.3801-04.2005

Copyright $\odot 2005$ Society for Neuroscience $\quad 0270-6474 / 05 / 251132-05 \$ 15.00 / 0$ gions of the CNS of females, possibly leading to a greater neuronal and behavioral response to cocaine. To assess this possibility, we used functional magnetic resonance imaging (MRI) to investigate the effect of estrogen treatment on cocaine-induced brain activation in the female rat. We report that estrogen enhanced the blood oxygen level-dependent (BOLD) response to cocaine within the hippocampus, ventral tegmental area (VTA), and nucleus accumbens after repeated administration. By itself, estrogen altered the BOLD response to hypercapnia, suggesting that this hormone may have effects on cerebrovascular reactivity. The present results could help understand the gender differences in cocaine addiction that have been reported in humans (Kosten et al., 1996; Magura et al., 1998; Elman et al., 2001).

\section{Materials and Methods}

Adult female Sprague Dawley rats (180-250 g) were purchased from Charles River Laboratories (Charles River, MA). Animals were housed in groups of two in a temperature- and humidity-controlled room under a $12 \mathrm{~h}$ light/dark cycle (lights off at 6 P.M.). Water and Purina rat chow (Nestlé Purina, St. Louis, MO) were provided ad libitum. All animals were acquired and cared for in accordance with the guidelines published in the Guide for the Care and Use of Laboratory Animals [National Institutes of Health (NIH) Publication 85-23, revised 1985] and in adherence to NIH and the American Association for Laboratory Animal Science guidelines.

SILASTIC implant preparation. SILASTIC tubing implants (inner diameter, $1.47 \mathrm{~mm}$; outer diameter, $1.97 \mathrm{~mm}$; $0.23 \mathrm{~mm}$ wall thickness) (Dow Corning 508-006; VWR Scientific, Bridgeport, NJ) were prepared according to Febo et al. (2002). Briefly, 5-mm-long sections of tubing were sealed on one end with SILASTIC silicone sealant (Dow Corning 732; VWR) and allowed to dry for $30 \mathrm{~min}$. Once dry, implants were either 
filled with crystalline 17- $\beta$-estradiol (Sigma-Aldrich, St. Louis, MO) or left empty; the other end was sealed off with additional sealant. Implants were air dried and incubated in $0.9 \%$ sterile saline for at least $12-16 \mathrm{~h}$. This allows the initial surge of high estradiol levels to be released from implants before use (Legan et al., 1975). SILASTIC implants achieve stable levels of plasma hormones that last well over $30 \mathrm{~d}$. The release rate depends on the length and wall thickness of the implant; for a 5-mm-long section with similar dimensions, the release rate has been estimated to be $\sim 75-100$ pg/ml per $24 \mathrm{~h}$ (Dziuk and Cook, 1966; Bridges, 1984). Previously, we have reported total plasma $17-\beta$-estradiol concentrations of $141.4 \pm 17.0 \mathrm{pg} / \mathrm{ml}$ (range, $94-192 \mathrm{pg} / \mathrm{ml}$ ) $15 \mathrm{~d}$ after initial subcutaneous placement in ovariectomized (Ovx) females (Febo et al., 2002). Ovx females with empty implants show nondetectable levels of estrogen $(<3$ $\mathrm{pg} / \mathrm{ml}$ ) (Febo et al., 2002).

Ovariectomy and estrogen administration. Rats were bilaterally ovariectomized under $2 \%$ isoflurane gas anesthetic. Implants were placed subcutaneously in the midscapular region during surgery. One-half of the animals received empty implants (Ovx); the other half received implants packed with crystalline $\beta$-estradiol [Ovx plus estrogen $(\mathrm{Ovx}+\mathrm{E})]$. Rats were given a $7 \mathrm{~d}$ recovery period to stabilize plasma estradiol concentrations before the start of experiments.

Cocaine administration. Cocaine administration and all experimental procedures were conducted during the light phase of the light/dark cycle. $\mathrm{Ovx}$ and $\mathrm{Ovx}+\mathrm{E}$ females were given a daily injection of cocaine (15 $\mathrm{mg} / \mathrm{kg}$, i.p.) for 5 consecutive days in their home cages. Control animals received an injection of $0.9 \%$ sterile saline $(0.1 \mathrm{cc} / 100 \mathrm{~g}$, i.p.). Animals remained injection free for 7 additional days. After the injection-free period, all animals were given an intracerebroventricular cocaine injection during functional imaging. Previously, we have reported greater behavioral sensitization and estrogen-dependent alterations in the dopaminergic (Febo et al., 2003), opioidergic (Febo et al., 2002), and GABAergic (Febo and Segarra, 2004) systems of Ovx +E females using this cocaine administration regimen. In summary, treatment groups were as follows: (1) Ovx rats given a single cocaine injection $(n=5),(2)$ Ovx rats given repeated cocaine injections $(n=5),(3) \mathrm{Ovx}+\mathrm{E}$ rats given a single cocaine injection $(n=4)$, and (4) $\mathrm{Ovx}+\mathrm{E}$ rats given repeated cocaine injections $(n=5)$.

MRI procedures. Details of the imaging procedures are given by Febo et al. (2004). Briefly, studies were performed with a dual-coil rat restrainer (Insight NeuroImaging Systems, Worcester, MA). Animals were acclimated to the restrainer and the imaging protocol before experiments. To reduce discomfort, a topical anesthetic ( $2 \%$ lidocaine gel) was applied to skin and soft tissue in the ear canal and over the bridge of the nose. Experiments were conducted in a Bruker Biospec 4.7-T/40 cm horizontal magnet (Oxford Instrument, Oxford, UK) equipped with a (Bruker, Billerica, MA) Biospec console. Challenge cocaine injections (20 $\mu \mathrm{g}$ in $10 \mu \mathrm{l}$ of artificial CSF) were made via the intracerebroventricular route while the animal was inside the magnet. This injection route and dose significantly reduce cardiac and respiratory alterations associated with peripheral psychostimulant administration (Febo et al., 2004). Immediately before imaging, rats were anesthetized under $2 \%$ isoflurane, the skull surface was exposed, and the landmark suture bregma was located. A cannula of polyethylene tubing (inner diameter, $0.28 \mathrm{~mm}$; outer diameter, $0.61 \mathrm{~mm})$ was implanted into the lateral cerebral ventricle $(1 \mathrm{~mm}$ caudal to bregma, $2 \mathrm{~mm}$ lateral to the midsagittal sinus, and $4 \mathrm{~mm}$ ventral to dura) and secured to the skull with surgical glue. Rats recovered for 45-60 min before cocaine administration and functional imaging. Intracerebroventricular cocaine injections were made via a plastic syringe connected at the end of the tubing. Cannula placement was verified before cocaine imaging with a short anatomical magnetic resonance scan. Only animals with correct placement were included in the study.

Twenty-five minutes before intracerebroventricular cocaine injections, a group of Ovx and Ovx $+\mathrm{E}$ rats was exposed to a $1 \mathrm{~min} 5 \% \mathrm{CO}_{2}$ pulse during a short functional scan $(3 \mathrm{~min})$ to assess cerebrovascular reactivity (Sicard et al., 2003). After this, high-resolution anatomical scans were collected using a fast spin echo pulse sequence [echo time (TE), $48 \mathrm{~ms}$; repetition time (TR), $2500 \mathrm{~ms}$; field of view (FOV), $3 \mathrm{~cm} ; 1.2$ $\mathrm{mm}$ slice thickness; $256 \times 256$ data matrix; 16 RareFactor]. Functional images were then obtained with a spin echo echoplanar imaging pulse

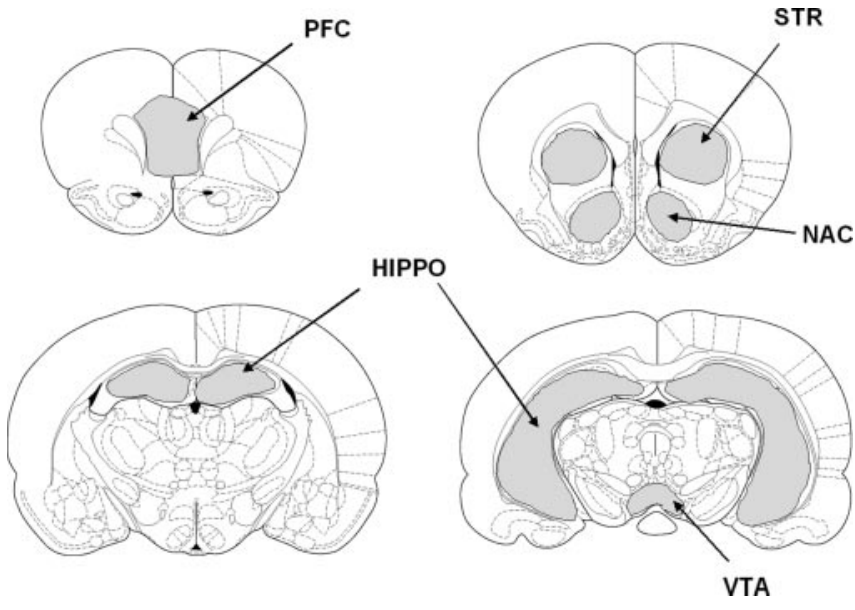

Figure 1. ROls analyzed for BOLD signal changes in response to cocaine. HIPPO, Hippocampus; NAC, nucleus accumbens; PFC, prefrontal cortex; STR, striatum.

sequence (FOV, $30 \mathrm{~mm}$; 12 slices; $1.2 \mathrm{~mm}$ thick; $64 \times 64$ data matrix; TE, $55 \mathrm{~ms}$; TR, $2000 \mathrm{~ms}$ ). Images were continuously acquired during $15 \mathrm{~min}$; that included a 5 min baseline and a 10 min period after intracerebroventricular cocaine injection.

Data analysis. Statistical analysis was performed using Stimulate software (Strupp, 1996). Movies of functional scans were generated and carefully examined to detect gross movements (i.e., frequent voxel displacements during time series), and the raw data time series were analyzed for course spikes. Regions of interest (ROIs) were drawn according to the atlas of the rat brain (Paxinos and Watson, 1997) and are shown in Figure 1. The ROIs included the nucleus accumbens, dorsal striatum, medial prefrontal cortex, hippocampus, and VTA. Selection of these ROIs was based on previous work showing effects of estrogen and cocaine within these areas (Woolley et al., 1997; Becker, 1999; Febo et al., 2003; Shansky et al., 2003; Febo and Segarra, 2004; Tang et al., 2004). It was hypothesized that the sensitization-enhancing effects of estrogen in the female would reflect changes in cocaine-induced neuronal activity within the selected ROI. Other brain areas that showed BOLD signal changes were not analyzed in this study. Before tracing the ROI, functional scans were aligned to a reference anatomical scan using the MRI analysis software ImageJ from Karl Schmidt (University of Massachusetts Medical School, Worcester, MA) (http://www.quickvol.com).

For each subject, signal intensity values for all pixels per ROI were normalized to their time series baseline (expressed as percentage change from baseline). The raw data were averaged during the first $5 \mathrm{~min}$ after cocaine injection to make intragroup (fixed-effects) statistical comparisons. A $t$ test was used to compare drug naive and cocaine-pretreated rats (95\% confidence level). Signal changes in response to cocaine were primarily increases (positive BOLD) and not decreases (negative BOLD); thus the data presented in Results are for positive signal changes. To generate positive BOLD activation maps, the composite functional maps were subjected to a pixel-by-pixel $t$ test comparing signal intensity during the $5 \mathrm{~min}$ preinjection baseline period and $5 \mathrm{~min}$ immediately after intracerebroventricular cocaine injection. Pixels for which the BOLD percentage change relative to the baseline period was significantly different at a $95 \%$ confidence level were overlaid onto the reference anatomical data set.

\section{Results}

Estrogen modulates the BOLD response to cocaine

A single cocaine injection increased BOLD activity in the prefrontal cortex, nucleus accumbens, striatum, VTA, and hippocampus (Fig. 2). Interestingly, cocaine-induced brain activity was dependent on estrogen treatment. Ovariectomized females, which have negligible plasma levels of estrogen $[2.7 \pm 1.2 \mathrm{pg} / \mathrm{ml}$ as reported by Febo et al. (2002)], showed greater BOLD percentage changes in response to cocaine than did Ovx $+\mathrm{E}$ rats (Fig. 2). 
This was observed throughout all ROIs. No significant differences in negative BOLD were observed within the ROIs studied.

\section{Estrogen modulates the BOLD response to hypercapnia}

Hypercapnia produced positive BOLD signal changes in both Ovx and Ovx +E animals (Fig. 2). The percentages of BOLD signal changes were greater in Ovx than in Ovx $+E$ rats, as was the number of positive BOLD pixels.

\section{Effect of repeated cocaine administration on the BOLD} response to cocaine: enhancement by estrogen

Repeated cocaine administration enhanced BOLD signal changes in the nucleus accumbens, striatum, hippocampus, and VTA of $\mathrm{Ovx}+\mathrm{E}$ rats compared with rats given acute cocaine (Fig. 3). $\mathrm{Ovx}+\mathrm{E}$ rats given repeated cocaine injections also showed a greater response in the nucleus accumbens, VTA, and hippocampus than did their Ovx counterparts (Fig. 3). As mentioned above, no significant differences in negative BOLD were observed within the ROIs studied.

\section{Discussion}

In female rats, estrogen enhances the psychomotor stimulant (Chin et al., 2002; Febo et al., 2003; Hu and Becker, 2003) and reinforcing effects of cocaine (Lynch et al., 2001). Substantial data support actions of estrogen through the mesolimbic dopamine system of female rats (Sakamoto et al., 1993; Thompson and Moss, 1994; Bosse et al., 1997; Becker, 1999; Febo et al., 2003, 2004). Our present data support effects of estrogen in other brain regions as well. In the present study, we observed that estrogen treatment was associated with a curtailed BOLD response to acute cocaine and with enhanced BOLD activation after repeated cocaine administration. The greater BOLD responses in chronically treated animals were observed within the nucleus accumbens, dorsal striatum, VTA, and hippocampus. The influential role of estrogen within these brain areas suggests that they may be involved in mediating the greater behavioral sensitization to cocaine reported in females (Chin et al., 2002; Febo et al., 2003; Hu and Becker, 2003).

The effects of estrogen treatment on acute cocaine-induced BOLD activity may arise from actions of estrogen on cerebral blood flow (CBF) as well as direct effects on neuronal activity and metabolism. In rats, cerebral metabolic rates for glucose $\left(\mathrm{CMR}_{\mathrm{glu}}\right)$, as measured by quantitative 2 - $\left[{ }^{14} \mathrm{C}\right]$ deoxyglucose (2-DG) in vitro autoradiography, differ between males and females and vary throughout the stages of the estrous cycle (Nehlig et al., 1985). High rates of $\mathrm{CMR}_{\mathrm{glu}}$ were observed in the nucleus accumbens, hippocampus, hypothalamus, and superior colliculus during proestrous (Nehlig et al., 1985), a stage of the rat estrous cycle characterized by highest estrogen levels in plasma (Neill et al., 1971). Similarly, estrogen treatment has been reported to increase CBF in postmenopausal women (Smith and Zubieta,
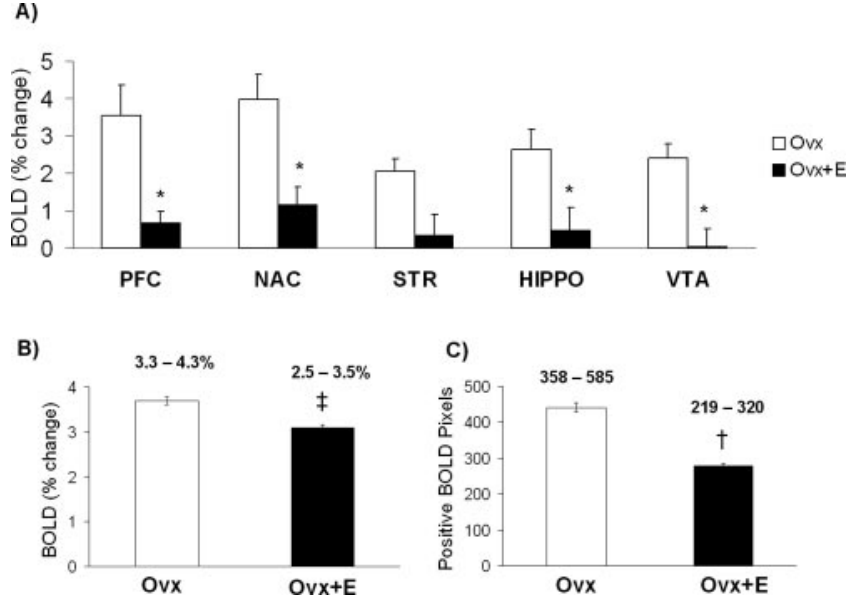

Figure 2. BOLD signal changes in response to acute cocaine or hypercapnia in Ovx and $0 \mathrm{vx}+\mathrm{E}$ rats. $A$, Cocaine-induced BOLD signal changes. $0 \mathrm{vx}+\mathrm{E}$ females showed a lower percentage change in BOLD response to cocaine than did $0 \mathrm{vx}$ females $\left({ }^{*} t_{7}=2.0 ; p<0.05\right.$ for all brain areas shown). $B$, Hypercapnia-induced BOLD signal changes. The percentages of BOLD signal changes were lower in $0 \mathrm{vx}+\mathrm{E}$ than in $0 \mathrm{vx}$ rats $\left({ }^{\ddagger} t_{10}=2.2 ; p=0.02\right)$. $C$, Number of positive BOLD pixels in response to hypercapnia. The number of positive BOLD pixels was lower in $0 \mathrm{vx}+\mathrm{E}$ than in $0 \mathrm{vx}$ rats $\left({ }^{\dagger} t_{10}=4.3 ; p=0.0007\right)$. The numbers above the bar graphs indicate the range of BOLD percentage changes and pixel numbers that were sampled from individual rats. Samples were taken from three contiguous rostral brain slices. All data are expressed as mean \pm SEM. HIPPO, Hippocampus; NAC, nucleus accumbens; PFC, prefrontal cortex; STR, striatum.
A)

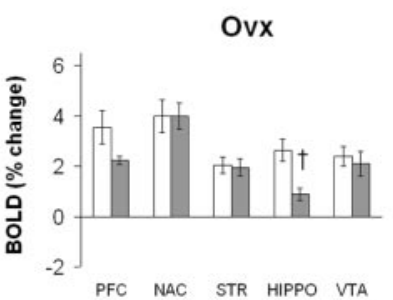

B)

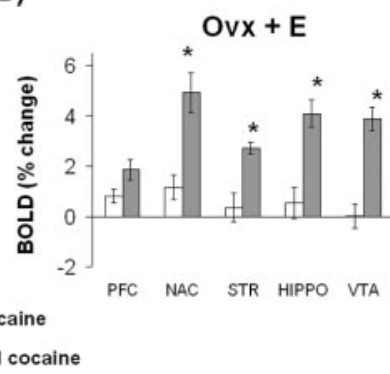

C)

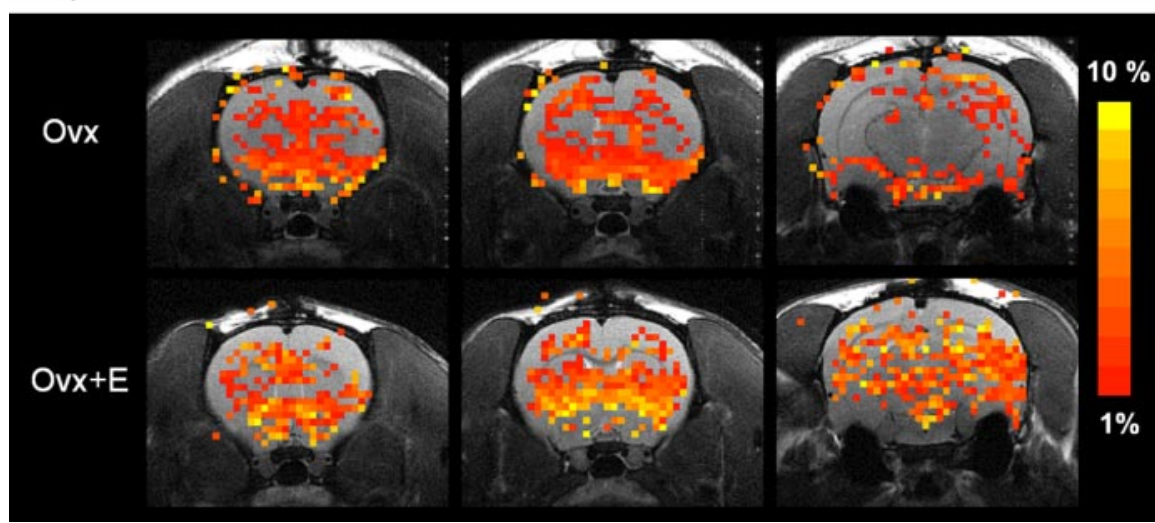

Figure 3. BOLD signal changes after repeated cocaine administration in $0 v x$ and $0 v x+E$ rats. $A, \ln 0 v x$ rats, there was a reduced $B O L D$ response in the hippocampus after repeated cocaine administration $\left({ }^{\dagger} t_{8}=1.8 ; p=0.01\right) \cdot B, 0 \mathrm{vx}+$ Efemales given repeated cocaine injections showed the greatest BOLD percentage changes in the nucleus accumbens, striatum, VTA, and hippocampus compared with those given a single cocaine injection $\left({ }^{*} t_{7}=1.9 ; p<0.05\right)$. Data are expressed as mean \pm SEM. $C$, Activation maps of cocaine-induced BOLD activity. Maps correspond to composite images of Ovx and Ovx $+E$ rats. Colored pixels represent brain areas that showed signal intensity values significantly different from baseline (scale bar hue indicates percentage change value). Statistical significance was determined using pixel-by-pixel $t$ test analysis comparing baseline with a cocaine injection period $(\alpha=0.05)$. $0 \mathrm{vx}+$ E rats showed a greater number of activated voxels in response to cocaine than did $0 \mathrm{vx}$ and intact rats. 
2001; Slopien et al., 2003). Increased $\mathrm{CMR}_{\mathrm{glu}}$ and CBF are likely associated, in part, with increased basal neuronal activity with estrogen treatment (Woolley et al., 1997). Indeed, states of increased basal neuronal activity reduce the magnitude of the BOLD response to sensory stimuli (Hyder et al., 2002). This is attributable to the fact that the magnitude of the BOLD signal response is determined, to a large extent, by basal CBF (Cohen et al., 2002). Greater basal neuronal activity and/or CBF might have caused lower positive BOLD signal changes in response to cocaine and hypercapnia in $\mathrm{Ovx}+\mathrm{E}$ rats. Evidence of enhanced basal neuronal activity with estrogen treatment comes from electrophysiological experiments showing increased frequency of spontaneous neuronal firing in hypothalamic and hippocampal slices associated with suppressed GABA-mediated inhibitory neurotransmission (Murphy et al., 1998; Parducz et al., 2002). We have reported recently that estrogen reduces $G_{A B A}$ receptor-mediated G-protein activation in the VTA of female rats (Febo and Segarra, 2004). This would suggest a reduction in $\mathrm{GABA}_{\mathrm{B}}$-mediated inhibition within this region, possibly resulting in increased basal dopamine neuron firing. This remains, however, in the realm of speculation. Finally, one cannot rule out the possibility that high and chronic levels of estrogen in plasma directly affect the cerebrovasculature and thereby alter BOLD signal changes in response to acute cocaine administration. This is partly supported by data showing reduced BOLD signal changes in response to $5 \% \mathrm{CO}_{2}$ in $\mathrm{Ovx}+\mathrm{E}$ rats.

Repeated cocaine administration in $\mathrm{Ovx}+\mathrm{E}$ rats resulted in enhanced BOLD activity within mesocorticolimbic brain regions. This did not occur in Ovx rats without steroid replacement, suggesting that the effect of repeated cocaine administration on neuronal activity in these areas is hormonally modulated. In male rats, it is well documented that repeated cocaine administration alters $\mathrm{CMR}_{\mathrm{glu}}$; this effect varies according to the duration of the abstinence period. For instance, positron emission tomography studies using $\left[{ }^{18} \mathrm{~F}\right]$ fluorodeoxyglucose show that metabolic activity in the frontal cortex increases with $<1$ week of abstinence but decreases with longer periods (Volkow et al., 1991, 1992). This has also been supported by 2-DG autoradiography in males (Hammer et al., 1993). Thus, these data show that the basal metabolism in the brain diminishes with chronic cocaine administration, as a function of abstinence duration. It is possible that in $\mathrm{Ovx}+\mathrm{E}$ females treated repeatedly with cocaine, basal metabolic activity was reduced after a $7 \mathrm{~d}$ abstinence period, and this could partially explain the greater magnitude change in BOLD signal intensity. Repeated cocaine administration induces longterm adaptations within mesocorticolimbic circuits, such as changes in c-fos expression (Hiroi et al., 1997; Canales and Graybiel, 2000; Todtenkopf et al., 2002) and dendritic spine density (Robinson and Kolb, 1999) that consequently affect synaptic transmission (Thomas et al., 2001; Beurrier and Malenka, 2002). These changes have also been reported in the female after estrogen administration (Segarra and McEwen, 1991; Woolley et al., 1997; Priest and Roberts, 2000).

A caveat in the present experimental design involves variation of the environment in which cocaine was administered and the route of administration. Both conditions surrounding psychostimulant administration and the route of administration can affect the behavioral response to these drugs (Browman et al., 1998) and perhaps neuronal activity (Porrino, 1993). Thus, external stimuli, such as a needle prick after intraperitoneal administration and the cage environment in which cocaine pretreatment was given, are not expected to significantly contribute to evoking neuronal activity in the present study.
Our present data suggest that repeated cocaine administration in Ovx + E rats leads to adaptations in mesolimbic and hippocampal neurons that enhance the magnitude of BOLD activation. One important action of estrogen in the hippocampus of females is to promote neuronal growth and remodeling, as observed by spine formation and dendritic sprouting (Kadish and Van Groen, 2002; Sakamoto et al., 2003; Li et al., 2004; Tang et al., 2004). Thus, cocaine-induced changes in synaptic plasticity observed in mesolimbic neurons of males (Kolb et al., 2003) could possibly be facilitated by the presence of estrogen in females (Segarra and McEwen, 1991). Additional studies will be needed to confirm this possibility. The present findings have important implications with regard to the issue of gender differences in cocaine addiction and other neuropsychiatric disorders. These findings also urge continued investigation of the role of gonadal steroids in determining the chronic effects of drugs of abuse on neuronal function in the CNS of both male and females.

\section{References}

Becker JB (1999) Gender differences in dopaminergic function in striatum and nucleus accumbens. Pharmacol Biochem Behav 64:803-812.

Beurrier C, Malenka RC (2002) Enhanced inhibition of synaptic transmission by dopamine in the nucleus accumbens during behavioral sensitization to cocaine. J Neurosci 22:5817-5822.

Bosse R, Rivest R, Di Paolo T (1997) Ovariectomy and estradiol treatment affect the dopamine transporter and its gene expression in the rat brain. Brain Res Mol Brain Res 46:343-346.

Bridges RS (1984) A quantitative analysis of the roles of dosage, sequence, and duration of estradiol and progesterone exposure in the regulation of maternal behavior in the rat. Endocrinology 114:930-940.

Browman KE, Badiani A, Robinson TE (1998) The influence of environment on the induction of sensitization to the psychomotor activating effects of intravenous cocaine in rats is dose-dependent. Psychopharmacology 137:90-98.

Canales JJ, Graybiel AM (2000) Patterns of gene expression and behavior induced by chronic dopamine treatments. Ann Neurol 47:S53-S59.

Chang AS, Chang SM (1999) Nongenomic steroidal modulation of highaffinity serotonin transport. Biochim Biophys Acta 1417:157-166.

Chin J, Sternin O, Wu HB, Burrell S, Lu D, Jenab S, Perrotti LI, QuinonesJenab V (2002) Endogenous gonadal hormones modulate behavioral and neurochemical responses to acute and chronic cocaine administration. Brain Res 945:123-130.

Cohen ER, Ugurbil K, Kim SG (2002) Effect of basal conditions on the magnitude and dynamics of the blood oxygenation level-dependent fMRI response. J Cereb Blood Flow Metab 22:1042-1053.

Dziuk PJ, Cook B (1966) Passage of steroids through silicone rubber. Endocrinology 78:208-211.

Elman I, Karlsgodt KH, Gastfriend DR (2001) Gender differences in cocaine craving among non-treatment-seeking individuals with cocaine dependence. Am J Drug Alcohol Abuse 27:193-202.

Febo M, Segarra AC (2004) Cocaine alters GABA $_{B}$-mediated G-protein activation in the ventral tegmental area of female rats: modulation by estrogen. Synapse 54:30-36.

Febo M, Jimenez-Rivera CA, Segarra AC (2002) Estrogen and opioids interact to modulate the locomotor response to cocaine in the female rat. Brain Res 943:151-161.

Febo M, Gonzalez-Rodriguez LA, Capo-Ramos DE, Gonzalez-Segarra NY, Segarra AC (2003) Estrogen-dependent alterations in D2/D3-induced $\mathrm{G}$ protein activation in cocaine-sensitized female rats. J Neurochem 86:405-412.

Febo M, Segarra AC, Tenney JR, Brevard ME, Duong TQ, Ferris CF (2004) Imaging cocaine-induced changes in the mesocorticolimbic dopaminergic system of conscious rats. J Neurosci Methods 39:167-176.

Hammer Jr RP, Pires WS, Markou A, Koob GF (1993) Withdrawal following cocaine self-administration decreases regional cerebral metabolic rate in critical brain reward regions. Synapse 14:73-80.

Hiroi N, Brown JR, Haile CN, Ye H, Greenberg ME, Nestler EJ (1997) FosB mutant mice: loss of chronic cocaine induction of Fos-related proteins and heightened sensitivity to cocaine's psychomotor and rewarding effects. Proc Natl Acad Sci USA 94:10397-10402. 
Hu M, Becker JB (2003) Effects of sex and estrogen on behavioral sensitization to cocaine in rats. J Neurosci 23:693-699.

Hyder F, Rothman DL, Shulman RG (2002) Total neuroenergetics support localized brain activity: implications for the interpretation of fMRI. Proc Natl Acad Sci USA 99:10771-10776.

Kadish I, Van Groen T (2002) Low levels of estrogen significantly diminish axonal sprouting after entorhinal cortex lesions in the mouse. J Neurosci 22:4095-4102.

Kolb B, Gorny G, Li Y, Samaha AN, Robinson TE (2003) Amphetamine or cocaine limits the ability of later experience to promote structural plasticity in the neocortex and nucleus accumbens. Proc Natl Acad Sci USA 100:10523-10528.

Kosten TR, Kosten TA, McDougle CJ, Hameedi FA, McCance EF, Rosen MI, Oliveto AH, Price LH (1996) Gender differences in response to intranasal cocaine administration to humans. Biol Psychiatry 39:147-148.

Lagrange AH, Wagner EJ, Ronnekleiv OK, Kelly MJ (1996) Estrogen rapidly attenuates a $\mathrm{GABA}_{\mathrm{B}}$ response in hypothalamic neurons. Neuroendocrinology 64:114-123.

Legan SJ, Coon GA, Karsch FJ (1975) Role of estrogen as initiator of daily LH surges in the ovariectomized rat. Endocrinology 96:50-56.

Li C, Brake WG, Romeo RD, Dunlop JC, Gordon M, Buzescu R, Magarinos AM, Allen PB, Greengard P, Luine V, McEwen BS (2004) Estrogen alters hippocampal dendritic spine shape and enhances synaptic protein immunoreactivity and spatial memory in female mice. Proc Natl Acad Sci USA 101:2185-2190.

Lynch WJ, Roth ME, Mickelberg JL, Carroll ME (2001) Role of estrogen in the acquisition of intravenously self-administered cocaine in female rats. Pharmacol Biochem Behav 68:641-646.

Magura S, Kang SY, Rosenblum A, Handelsman L, Foote J (1998) Gender differences in psychiatric comorbidity among cocaine-using opiate addicts. J Addict Dis 17:49-61.

Murphy DD, Cole NB, Greenberger V, Segal M (1998) Estradiol increases dendritic spine density by reducing GABA neurotransmission in hippocampal neurons. J Neurosci 18:2550-2559.

Nehlig A, Porrino LJ, Crane AM, Sokoloff L (1985) Local cerebral glucose utilization in normal female rats: variations during the estrous cycle and comparison with males. J Cereb Blood Flow Metab 5:393-400.

Neill JD, Freeman ME, Tillson SA (1971) Control of the proestrus surge of prolactin and luteinizing hormone secretion by estrogens in the rat. Endocrinology 89:1448-1453.

Parducz A, Hoyk Z, Kis Z, Garcia-Segura LM (2002) Hormonal enhancement of neuronal firing is linked to structural remodelling of excitatory and inhibitory synapses. Eur J Neurosci 16:665-670.

Paxinos G, Watson C (1997) The rat brain in stereotaxic coordinates, Ed 3. Boston: Academic.

Porrino LJ (1993) Functional consequences of acute cocaine treatment depend on route of administration. Psychopharmacology 112:343-351.

Priest CA, Roberts JL (2000) Estrogen and tamoxifen differentially regulate $\beta$-endorphin and cFos expression and neuronal colocalization in the arcuate nucleus of the rat. Neuroendocrinology 72:293-305.

Robinson TE, Kolb B (1999) Alterations in the morphology of dendrites and dendritic spines in the nucleus accumbens and prefrontal cortex following repeated treatment with amphetamine or cocaine. Eur J Neurosci 11:1598-1604.
Sakamoto H, Mezaki Y, Shikimi H, Ukena K, Tsutsui K (2003) Dendritic growth and spine formation in response to estrogen in the developing Purkinje cell. Endocrinology 144:4466-4477.

Sakamoto Y, Suga S, Sakuma Y (1993) Estrogen-sensitive neurons in the female rat ventral tegmental area: a dual route for the hormone action. J Neurophysiol 70:1469-1475.

Segarra AC, McEwen BS (1991) Estrogen increases spine density in ventromedial hypothalamic neurons of peripubertal rats. Neuroendocrinology 54:365-372.

Shansky RM, Glavis-Bloom C, Lerman D, McRae P, Benson C, Miller K, Cosand L, Horvath TL, Arnsten AF (2003) Estrogen mediates sex differences in stress-induced prefrontal cortex dysfunction. Mol Psychiatry 9:531-538.

Sicard K, Shen Q, Brevard ME, Sullivan R, Ferris CF, King JA, Duong TQ (2003) Regional cerebral blood flow and BOLD responses in conscious and anesthetized rats under basal and hypercapnic conditions: implications for functional MRI studies. J Cereb Blood Flow Metab 23:472-481.

Sircar R, Kim D (1999) Female gonadal hormones differentially modulate cocaine-induced behavioral sensitization in Fischer, Lewis, and SpragueDawley rats. J Pharmacol Exp Ther 289:54-65.

Slopien R, Junik R, Meczekalski B, Halerz-Nowakowska B, Maciejewska M, Warenik-Szymankiewicz A, Sowinski J (2003) Influence of hormonal replacement therapy on the regional cerebral blood flow in postmenopausal women. Maturitas 46:255-262.

Smith YR, Zubieta JK (2001) Neuroimaging of aging and estrogen effects on central nervous system physiology. Fertil Steril 76:651-659.

Strupp JP (1996) Stimulate: a GUI based fMRI analysis software package. NeuroImage 3:S607.

Tang Y, Janssen WG, Hao J, Roberts JA, McKay H, Lasley B, Allen PB, Greengard P, Rapp PR, Kordower JH, Hof PR, Morrison JH (2004) Estrogen replacement increases spinophilin-immunoreactive spine number in the prefrontal cortex of female rhesus monkeys. Cereb Cortex 14:215-223.

Thomas MJ, Beurrier C, Bonci A, Malenka RC (2001) Long-term depression in the nucleus accumbens: a neural correlate of behavioral sensitization to cocaine. Nat Neurosci 4:1217-1223.

Thompson TL, Moss RL (1994) Estrogen regulation of dopamine release in the nucleus accumbens: genomic- and nongenomic-mediated effects. J Neurochem 62:1750-1756.

Todtenkopf MS, Mihalakopoulos A, Stellar JR (2002) Withdrawal duration differentially affects $c-f o s$ expression in the medial prefrontal cortex and discrete subregions of the nucleus accumbens in cocaine-sensitized rats. Neuroscience 114:1061-1069.

Volkow ND, Fowler JS, Wolf AP, Hitzemann R, Dewey S, Bendriem B, Alpert R, Hoff A (1991) Changes in brain glucose metabolism in cocaine dependence and withdrawal. Am J Psychiatry 148:621-626.

Volkow ND, Hitzemann R, Wang GJ, Fowler JS, Wolf AP, Dewey SL, Handlesman L (1992) Long-term frontal brain metabolic changes in cocaine abusers. Synapse 11:184-190.

Woolley CS, Weiland NG, McEwen BS, Schwartzkroin PA (1997) Estradiol increases the sensitivity of hippocampal CA1 pyramidal cells to NMDA receptor-mediated synaptic input: correlation with dendritic spine density. J Neurosci 17:1848-1859. 